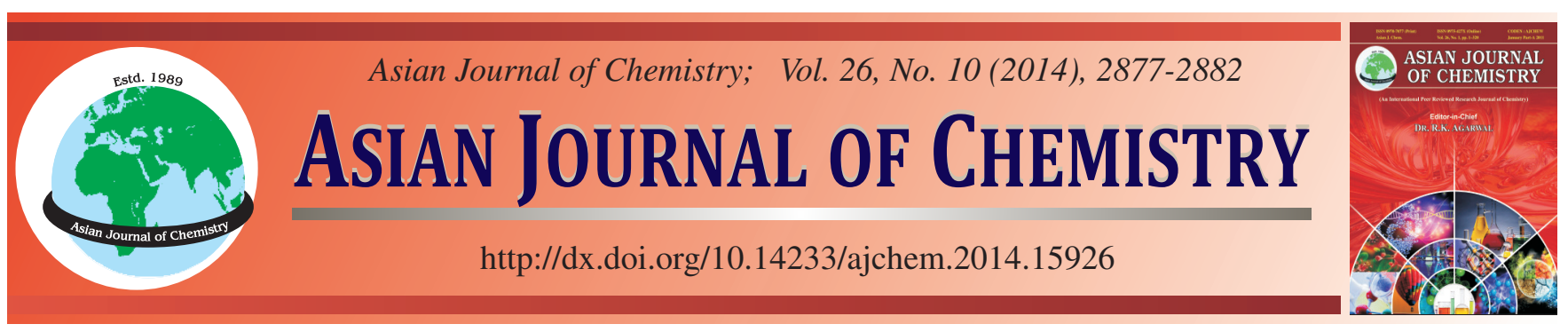

\title{
High Performance Liquid Chromatographic Simultaneous Analysis for Quantitation of Eight Marker Compounds of Traditional Korean Medicine, Ssanghwa-Tang
}

\author{
C.S. SEO, J.H. KIM and H.K. SHIN ${ }^{*}$
}

Herbal Medicine Formulation Research Group, Korea Institute of Oriental Medicine, 1672 Yuseongdae-ro, Yuseong-gu, Daejeon 305-811, Republic of Korea

*Corresponding author: Fax: +82 42864 2120; Tel: +82 42868 9464; E-mail: hkshin@kiom.re.kr

Received: 17 June 2013;

Accepted: 28 October 2013;

Published online: 10 May 2014;

AJC-15139

\begin{abstract}
We performed simultaneous quantitation of eight components, 5-(hydroxymethyl)-2-furaldehyde (5-HMF), albiflorin, paeoniflorin, liquiritin, ferulic acid, cinnamic acid, cinnamaldehyde and glycyrrhizin of Ssanghwa-tang using high-performance liquid chromatographyphotodiode array. A Luna C18 column was used as the analytical column for separation of the eight compounds. The mobile phase used gradient elution with $1 \%(\mathrm{v} / \mathrm{v})$ aqueous acetic acid (A) and $1 \%(\mathrm{v} / \mathrm{v})$ acetic acid in acetonitrile (B). The flow rate was $1 \mathrm{~mL} / \mathrm{min}$, column temperature was maintained at $40{ }^{\circ} \mathrm{C}$ and the injection volume was $10 \mu \mathrm{L}$. The PDA detector was monitored in the range $190-400 \mathrm{~nm}$. Calibration curves of the eight compounds showed good linearity $\left(r^{2} \geq 0.9998\right)$. The recoveries of the eight compounds were $92.80-$ $103.43 \%$. The relative standard deviations of intraday and interday precision were $0.07-2.03$ and $0.08-1.78 \%$, respectively. The concentrations of the eight marker components were $0.148-12.261 \mathrm{mg} / \mathrm{g}$.
\end{abstract}

Keywords: Simultaneous analysis, Ssanghwa-tang, Traditional korean medicine, HPLC.

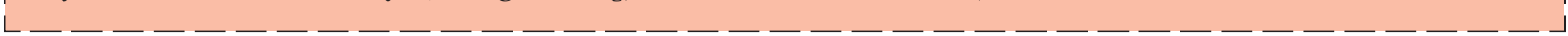

\section{INTRODUCTION}

Traditional herbal medicines typically contain multiple herbs, which contain several ingredients and have been widely used to prevent and treat a variety of diseases. Moreover, they also have few or no side effects compared with western medicines or synthetic drugs. Ssanghwa-tang, also called Shuanghetang in Chinese, is one of the Korean traditional medicines, consisting of nine species of herbal medicines, Paeoniae Radix, Rehmanniae Radix Preparata, Astragali Radix, Angelicae Gigantis Radix, Cnidii Rhizoma, Cinnamomi Cortex, Glycyrrhizae Radix et Rhizoma, Zingi-beris Rhizoma Crudus and Zizyphi Fructus ${ }^{1}$. It has been commonly used as a herbal medicine for thousands of years in Korea for recovery from fatigue and alleviation of fever and headache ${ }^{1,2}$. Pharmacological effects of Ssanghwa-tang were investigated in vitro and in vivo for antifatigue ${ }^{3,4}$, hepatorestoring ${ }^{5}$ and antiinflammatory ${ }^{6}$ effects. Recently, a study on the cytochrome P450-mediated herb-drug interaction of Ssanghwa-tang has been reported ${ }^{7}$. In the present study, we performed a simultaneous determination of eight marker components, albiflorin and paeoniflorin in Paeoniae Radix, 5-(hydroxymethyl)-2furaldehyde (5-HMF) in Rehmanniae Radix, ferulic acid in Cnidii Rhizoma, cinnamic acid and cinnamaldehyde in Cinnamomi Cortex and liquiritin and glycyrrhizin in Glycyr- rhizae Radix et Rhizoma for quality control of Ssanghwa-tang using the accurate and convenient high-performance liquid chromatography-photodiode array (HPLC-PDA) method. The chemical structures of these compounds are shown in Fig. 1.

\section{EXPERIMENTAL}

Reference standards, 5-(hydroxymethyl)-2-furaldehyde (5-HMF) and cinnamic acid were purchased from SigmaAldrich (St. Louis, MO, USA) and albiflorin, paeoniflorin, cinnamaldehyde, ferulic acid, liquiritin and glycyrrhizin were purchased from Wako (Osaka, Japan). The purities of the eight reference compounds were $\geq 98.0 \%$ according to HPLC analysis. HPLC-grade, methanol and acetonitrile were obtained from J.T. Baker (Phillipsburg, NJ, USA) and water was purchased from Burdick \& Jackson (SK Chemical, Ulsan, Korea). Analytical reagent grade, glacial acetic acid was purchased from Merck KGaA (Darmstadt, Germany). Each herbal medicine component of Ssanghwa-tang, which consists of nine herbal medicines (Table-1), was purchased from Omniherb (Yeongcheon, Korea) and HMAX (Jecheon, Korea). The origin of each herbal medicine was taxonomically confirmed by Prof. Je Hyun Lee, Dongguk University, Gyeongju, Korea. Voucher specimens (2008-KE21-1 through KE21-9) have been deposited at the Basic Herbal Medicine Research Group, Korea Institute of Oriental Medicine. 


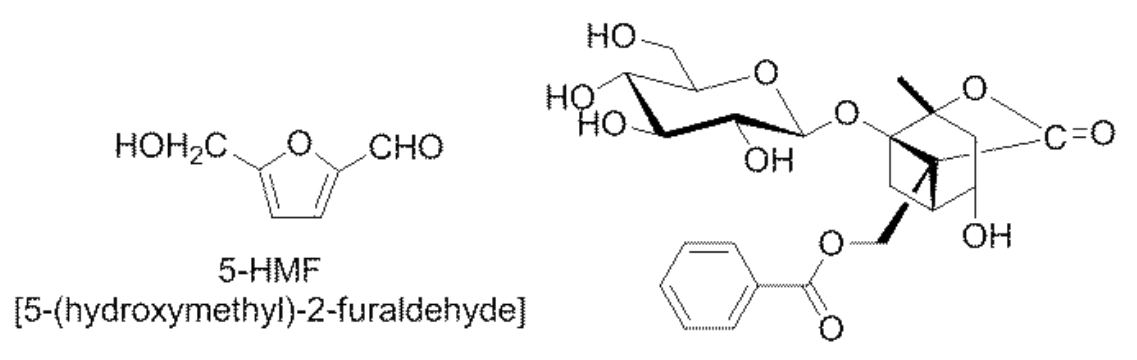

Albiflorin

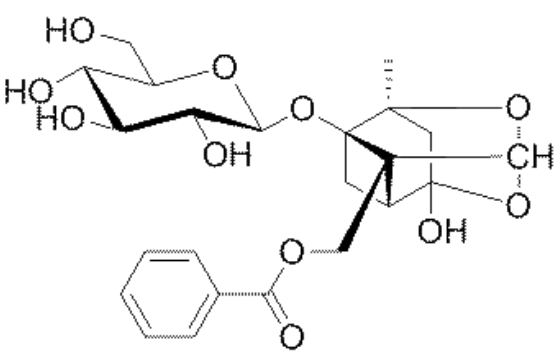

Paeoniflorin<smiles>COc1cc(/C=C/C(=O)O)ccc1O</smiles>

Ferulic acid<smiles>O=C(O)/C=C/c1ccccc1</smiles>

Cinnamic acid<smiles>O=C/C=C/c1ccccc1</smiles>

Cinnamaldehyde<smiles>O=C1C[C@H](c2ccc(OC3OC(CO)C(O)[C@@H](O)[C@H]3O)cc2)Oc2cc(O)ccc21</smiles>

Liquiritin

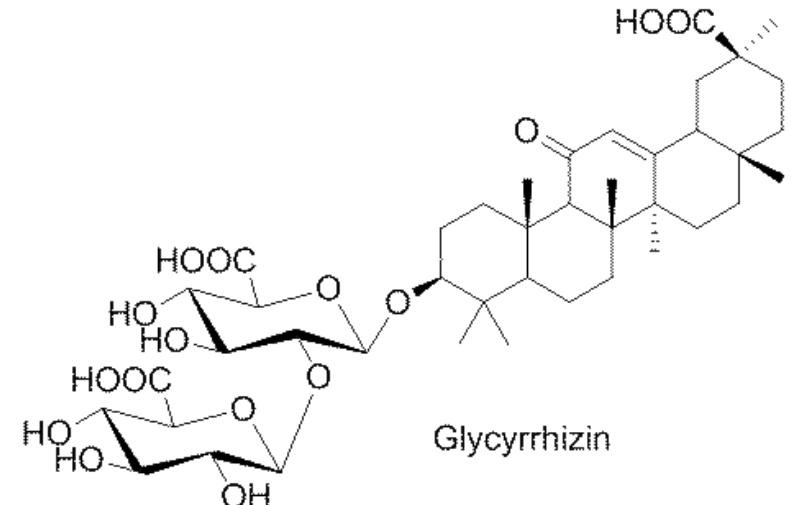

Fig. 1. Chemical structures of the eight marker compounds in ssanghwa-tang

\begin{tabular}{|c|c|c|c|}
\hline \multicolumn{4}{|c|}{$\begin{array}{c}\text { TABLE-1 } \\
\text { COMPOSITION OF SSANGHWA-TANG }\end{array}$} \\
\hline Latin name & Amount (g) & Supplier & Location \\
\hline $\begin{array}{l}\text { Paeoniae } \\
\text { Radix }\end{array}$ & 9.375 & Omniherb & Hwasun, Korea \\
\hline $\begin{array}{l}\text { Rehmanniae } \\
\text { Radix } \\
\text { Preparata }\end{array}$ & 3.75 & Omniherb & Jangheung, Korea \\
\hline $\begin{array}{l}\text { Astragali } \\
\text { Radix }\end{array}$ & 3.75 & Omniherb & Jeongseon, Korea \\
\hline $\begin{array}{l}\text { Angelicae } \\
\text { Gigantis Radix }\end{array}$ & 3.75 & Omniherb & Yeongcheon, Korea \\
\hline $\begin{array}{l}\text { Cnidii } \\
\text { Rhizoma }\end{array}$ & 3.75 & Omniherb & Yeongcheon, Korea \\
\hline $\begin{array}{l}\text { Cinnamomi } \\
\text { Cortex }\end{array}$ & 2.8125 & HMAX & Vietnam \\
\hline $\begin{array}{l}\text { Glycyrrhizae } \\
\text { Radix et } \\
\text { Rhizoma }\end{array}$ & 2.8125 & HMAX & China \\
\hline $\begin{array}{l}\text { Zingiberis } \\
\text { Rhizoma } \\
\text { Crudus }\end{array}$ & 3.75 & Omniherb & Seosan, Korea \\
\hline $\begin{array}{l}\text { Zizyphi } \\
\text { Fructus }\end{array}$ & 3.75 & Omniherb & Yeongcheon, Korea \\
\hline Total amount & 37.5 & & \\
\hline
\end{tabular}

The HPLC data were recorded using the Shimadzu Prominence LC-20A series (Shimadzu, Kyoto, Japan) equipped with a pump, online degasser, column oven, autosampler and PDA detector. The data were acquired and processed using LC solution software (Version 1.24, Shimadzu, Kyoto, Japan). The components were separated on a $250 \mathrm{~mm} \times 4.6 \mathrm{~mm}$ Phenomenex Luna C18 column with $5 \mathrm{~mm}$ particle size (Torrance, CA, USA). The gradient elution of mobile phases A $(1.0 \% \mathrm{v} / \mathrm{v}$ acetic acid in water $)$ and $\mathrm{B}(1.0 \% \mathrm{v} / \mathrm{v}$ acetic acid in acetonitrile) was performed as follows: 0-40 min, 5-70\% B; 40-45 min, 70-100\% B; 45-50 min, $100 \% \mathrm{~B}$; 50-55 min, $100-5 \% \mathrm{~B} ; 55-70 \mathrm{~min}, 5 \% \mathrm{~B}$. The flow rate was $1 \mathrm{~mL} / \mathrm{min}$, column temperature was maintained at $40{ }^{\circ} \mathrm{C}$ and injection volume was $10 \mathrm{~mL}$. The PDA detector was monitored in the range 190-400 $\mathrm{nm}$.

Preparation of standard solutions: Eight reference compounds 5-HMF, albiflorin, paeoniflorin, liquiritin, ferulic acid, cinnamic acid, cinnamaldehyde and glycyrrhizin were dissolved in methanol at a concentration of $1.0 \mathrm{mg} / \mathrm{mL}$. Each standard stock solution was stored at $4^{\circ} \mathrm{C}$ and used after serial dilution with methanol before HPLC analysis. 
Preparation of sample solutions: Ssanghwa-tang, which consists of nine medicinal herbals, was mixed to produce 3.5 $\mathrm{kg}(37.5 \mathrm{~g} \times 93.3)$ in the ratio in Table- 1 and extracted in a 10fold mass of distilled water at $100{ }^{\circ} \mathrm{C}$ for $2 \mathrm{~h}$. After filtration of the water solution, the solution was evaporated at $60{ }^{\circ} \mathrm{C}$ to dryness and freeze-dried. The yield of Ssanghwa-tang extract was $767.5 \mathrm{~g}(21.9 \%)$. For HPLC analysis, $500 \mathrm{mg}$ of the powdered Ssanghwa-tang extract was dissolved in $25 \mathrm{~mL}$ of HPLCgrade water and the solution was filtered by passing through a $0.2 \mathrm{~mm}$ syringe filter (Woongki Science, Seoul, Korea) before injection into the HPLC system.

Calibration curve, limits of detection (LOD) and limits of quantification (LOQ): For the calibration curves, each concentration was measured in triplicate. The calibration curve of each analyte was calculated by plotting the peak areas (y) versus the corresponding concentrations $(\mathrm{x}, \mathrm{mg} / \mathrm{mL})$ from standard solutions. The mixed stock solutions of reference compounds were diluted with methanol to evaluate LOD and LOQ values. The LOD and LOQ data were determined at signal-to-noise $(\mathrm{S} / \mathrm{N})$ ratios of 3 and 10, respectively.

Precision and recovery: Intraday and interday variations, which were used to evaluate the precision of the new HPLC method, were determined using the standard addition method for the samples spiked with low, middle and high concentration levels to prepare samples. The relative standard deviation was used as a measure of precision. To confirm the repeatability, six replicates using the mixed standard solutions were measured and evaluated. The RSD values of peak areas and retention times of each compound were used to evaluate the method repeatability. A recovery test was used to evaluate the accuracy of the developed method. The recovery test was performed by adding known amounts of low, middle and high concentration levels of standard solutions to $500 \mathrm{mg}$ of Ssanghwa-tang sample. This test was performed using the calibration curves of each compound.

\section{RESULTS AND DISCUSSION}

Optimization of chromatographic conditions: The HPLC conditions were optimized to improve the simultaneous analysis of the analytes with parameters such as mobile phase composition, gradient program and UV wavelength. As a result, we obtained satisfactory separation chromatograms using two mobile phase systems, $1 \%$ acetic acid in water (A) and $1 \%$ acetic acid in acetonitrile (B) with gradient elution. Quantitation was achieved using PDA detection at $230 \mathrm{~nm}$ for albiflorin and paeoniflorin, $254 \mathrm{~nm}$ for glycyrrhizin, $280 \mathrm{~nm}$ for 5-HMF, liquiritin, cinnamic acid and cinnamaldehyde and $320 \mathrm{~nm}$ for ferulic acid, based on retention time and UV spectra compared with those of the standards. Using the optimized chromatography conditions, the eight compounds eluted within $35 \mathrm{~min}$ and showed good system suitability without interference from other compounds (Table-2). Typical HPLC chromatograms of standards and the Ssanghwa-tang extracts are shown in Fig. 2.

\begin{tabular}{lcccc} 
SYSTEM SUITABILITY OF THE EIGHT MARKER COMPOUNDS \\
\hline \multicolumn{1}{c}{ Compound } & $\begin{array}{c}\text { Capacity } \\
\text { factor } \\
\left(\mathrm{k}^{\prime}\right)\end{array}$ & $\begin{array}{c}\text { Separation } \\
\text { factor }(\alpha)\end{array}$ & $\begin{array}{c}\text { Number of } \\
\text { theoretical } \\
\text { plates }(\mathrm{N})\end{array}$ & $\begin{array}{c}\text { Resolution } \\
(\mathrm{Rs})\end{array}$ \\
\hline 5-HMF & 1.70 & 2.28 & 1432 & 9.87 \\
Albiflorin & 3.89 & 1.06 & 15495 & 1.21 \\
Paeoniflorin & 4.13 & 1.06 & 6935 & 1.21 \\
Liquiritin & 4.59 & 1.07 & 17022 & 1.35 \\
Ferulic acid & 4.90 & 1.07 & 7164 & 1.35 \\
Cinnamic acid & 7.37 & 1.12 & 15616 & 5.57 \\
Cinnamaldehyde & 8.24 & 1.11 & 731303 & 6.29 \\
Glycyrrhizin & 9.10 & 1.11 & 30313 & 6.29 \\
\hline
\end{tabular}

Linearity, range, LOD and LOQ: The linearity was determined from the coefficient of determination $\left(r^{2}\right)$. It was found that the eight compounds showed good linearity with $r^{2} \geq$ 0.9998 in the test range of $0.39-500.00 \mathrm{mg} / \mathrm{mL}$. The LODs and LOQs for the eight tested compounds were 0.01-1.17 and 0.04-3.90 mg/mL, respectively (Table-3).

Recovery and precision: The recoveries of the eight compounds were in the range of 92.80-103.43\% at different concentrations and the RSD values were less than $2.10 \%$. The results of recovery are shown in Table-4. The RSD for repeatability of the eight analytes was less $0.55 \%$ for peak responses and less than $0.09 \%$ for retention times (data not shown). Thus, the HPLC assay showed good repeatability under optimized conditions. Table- 5 summarizes the intraday and interday precision and accuracy for the eight compounds evaluated by analyzing the Ssanghwa-tang sample. The precisions of intraday and interday variation were both better than $2.5 \%$ for each analyte. These results suggested that the present method has a satisfactory recovery, repeatability and precision.

Sample analysis: The newly established HPLC-PDA method was applied to determine simultaneously the amount of the eight marker compounds in the traditional Korean

TABLE-3

REGRESSION EQUATIONS, LINEARITY, LIMITS OF DETECTION (LOD) AND LIMITS OF QUANTIFICATION (LOQ) OF THE EIGHT MARKER COMPOUNDS

\begin{tabular}{|c|c|c|c|c|c|}
\hline Compound & Linear range $(\mu \mathrm{g} / \mathrm{mL})$ & Regression equation $^{a}$ & Correlation coefficient & $\operatorname{LOD}^{\mathrm{b}}(\mu \mathrm{g} / \mathrm{mL})$ & $\operatorname{LOQ}^{c}(\mu \mathrm{g} / \mathrm{mL})$ \\
\hline 5-HMF & $0.39-50.00$ & $y=80026.86 x+8129.07$ & 0.9999 & 0.04 & 0.13 \\
\hline Albiflorin & $2.34-300.00$ & $y=9011.42 x+6847.49$ & 0.9999 & 1.17 & 3.90 \\
\hline Paeoniflorin & $3.91-500.00$ & $y=12480.90 x+11075.11$ & 0.9998 & 0.98 & 3.26 \\
\hline Liquiritin & $1.56-200.00$ & $y=15722.74 x+12906.13$ & 0.9998 & 0.13 & 0.42 \\
\hline Ferulic acid & $1.56-200.00$ & $y=55545.33 x-13386.57$ & 0.9999 & 0.01 & 0.04 \\
\hline Cinnamic acid & $0.39-50.00$ & $y=82073.25 x+14007.28$ & 0.9999 & 0.03 & 0.10 \\
\hline Cinnamaldehyde & $1.64-105.00$ & $y=128853.62 x-5379.12$ & 0.9998 & 0.03 & 0.09 \\
\hline Glycyrrhizin & $1.56-200.00$ & $y=8021.54 x+3838.22$ & 1.0000 & 0.16 & 0.54 \\
\hline
\end{tabular}

${ }^{\mathrm{a}} y$ : peak area $(\mathrm{mAU})$ of compounds; $x$ : concentration $(\mu \mathrm{g} / \mathrm{mL})$ of compounds, ${ }^{b} \mathrm{LOD}=3 \times$ signal-to-noise ratio, ${ }^{c} \mathrm{LOQ}=10 \times$ signal-to-noise ratio 


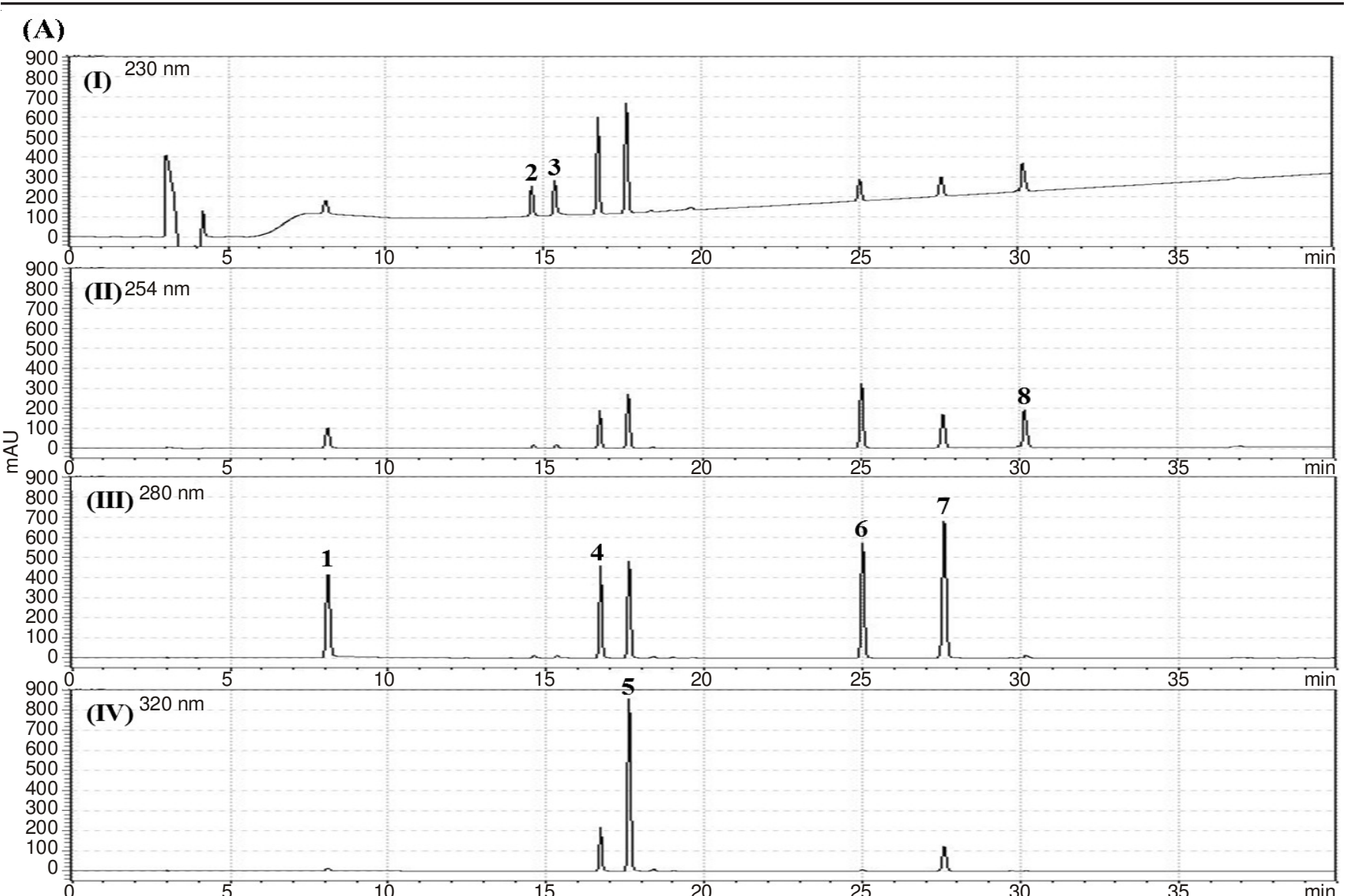

(B)
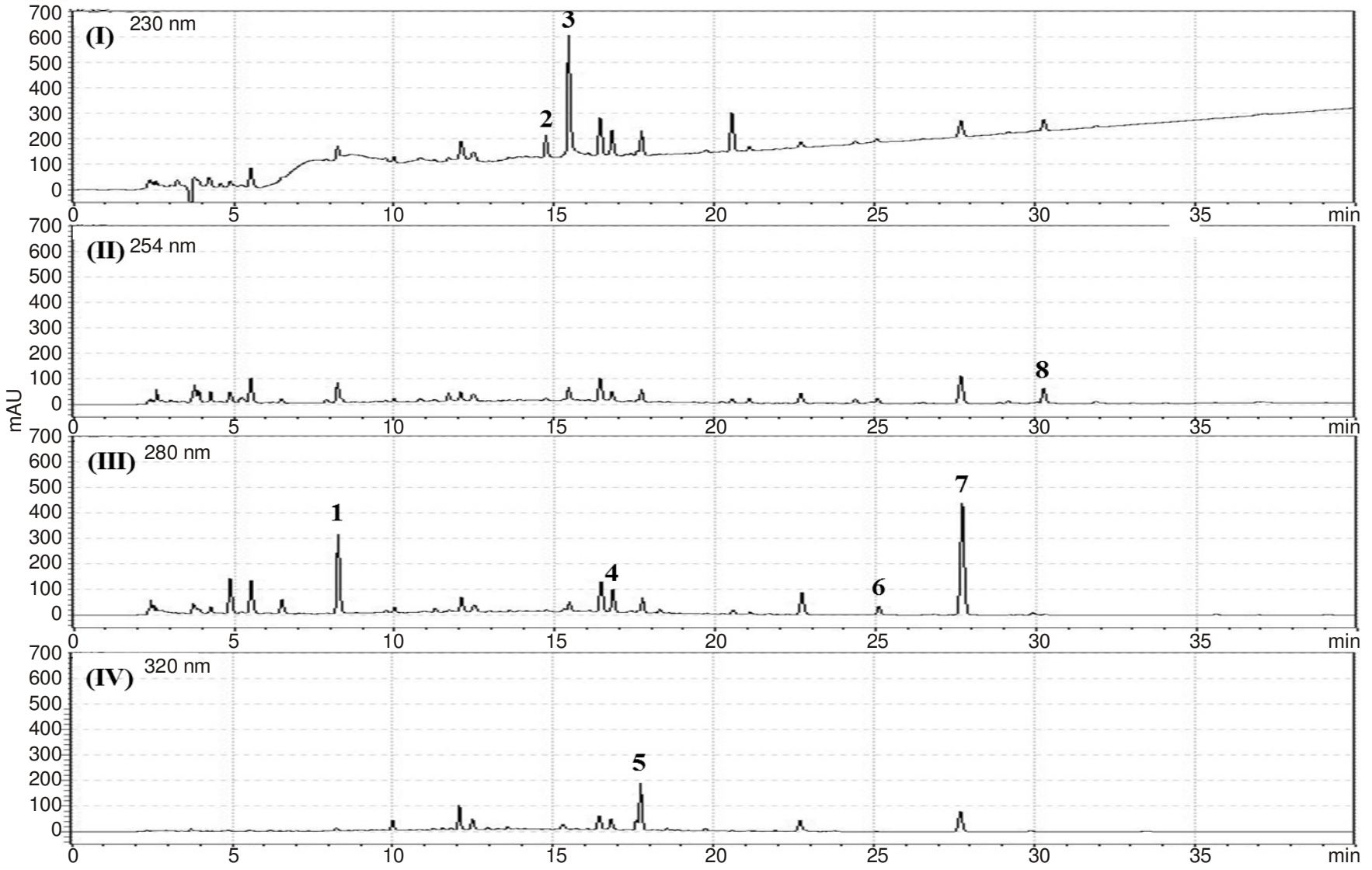

Fig. 2. HPLC chromatograms of a standard mixtures (A) and ssanghwa-tang extracts (B) at $230 \mathrm{~nm}$ (I), $254 \mathrm{~nm}$ (II), $280 \mathrm{~nm}$ (III) and $320 \mathrm{~nm}$ (IV). 5-HMF (1), albiflorin (2), paeoniflorin (3), liquiritin (4), ferulic acid (5), cinnamic acid (6), cinnamaldehyde (7) and glycyrrhizin (8) 


\begin{tabular}{|c|c|c|c|c|c|}
\hline \multicolumn{6}{|c|}{$\begin{array}{c}\text { TABLE-4 } \\
\text { RECOVERIES FOR THE ASSAY OF THE EIGHT INVESTIGATED COMPOUNDS IN SSANGHWA-TANG }\end{array}$} \\
\hline Analytes & Original conc. $(\mu \mathrm{g} / \mathrm{mL})$ & Spiked conc. $(\mu \mathrm{g} / \mathrm{mL})$ & Found conc. $(\mu \mathrm{g} / \mathrm{mL})$ & Recovery $^{\mathrm{a}} \pm \mathrm{SD}(\%)$ & $\operatorname{RSD}(\%)$ \\
\hline \multirow{3}{*}{ 5-HMF } & \multirow{3}{*}{13.44} & 3.00 & 16.44 & $99.80 \pm 0.84$ & 0.84 \\
\hline & & 7.50 & 20.87 & $98.85 \pm 1.18$ & 1.19 \\
\hline & & 15.00 & 28.24 & $98.64 \pm 0.84$ & 0.85 \\
\hline \multirow{3}{*}{ Albiflorin } & \multirow{3}{*}{21.87} & 6.00 & 27.85 & $99.59 \pm 1.38$ & 1.39 \\
\hline & & 15.00 & 36.62 & $98.35 \pm 2.05$ & 2.09 \\
\hline & & 30.00 & 51.16 & $97.62 \pm 0.62$ & 0.64 \\
\hline \multirow{3}{*}{ Paeoniflorin } & \multirow{3}{*}{108.62} & 10.00 & 118.62 & $99.99 \pm 1.00$ & 1.00 \\
\hline & & 25.00 & 133.19 & $98.31 \pm 0.81$ & 0.82 \\
\hline & & 50.00 & 158.56 & $99.88 \pm 0.75$ & 0.75 \\
\hline \multirow{3}{*}{ Liquiritin } & \multirow{3}{*}{31.31} & 4.00 & 35.34 & $100.71 \pm 1.39$ & 1.38 \\
\hline & & 10.00 & 41.62 & $103.17 \pm 0.34$ & 0.33 \\
\hline & & 20.00 & 51.99 & $103.43 \pm 0.28$ & 0.27 \\
\hline \multirow{3}{*}{ Ferulic acid } & \multirow{3}{*}{12.29} & 2.00 & 14.27 & $98.86 \pm 1.30$ & 1.31 \\
\hline & & 5.00 & 17.18 & $97.76 \pm 2.02$ & 2.07 \\
\hline & & 10.00 & 21.75 & $94.56 \pm 1.26$ & 1.34 \\
\hline \multirow{3}{*}{ Cinnamic acid } & \multirow{3}{*}{1.40} & 1.00 & 2.39 & $98.78 \pm 1.22$ & 1.23 \\
\hline & & 2.00 & 3.38 & $98.89 \pm 0.78$ & 0.79 \\
\hline & & 4.00 & 5.51 & $102.55 \pm 1.10$ & 1.07 \\
\hline \multirow{3}{*}{ Cinnamaldehyde } & \multirow{3}{*}{21.60} & 4.00 & 25.56 & $99.13 \pm 0.36$ & 0.36 \\
\hline & & 10.00 & 31.50 & $98.97 \pm 1.00$ & 1.01 \\
\hline & & 20.00 & 40.28 & $93.41 \pm 0.84$ & 0.90 \\
\hline \multirow{3}{*}{ Glycyrrhizin } & \multirow{3}{*}{29.13} & 6.00 & 34.99 & $97.64 \pm 1.42$ & 1.45 \\
\hline & & 15.00 & 43.05 & $92.80 \pm 0.68$ & 0.73 \\
\hline & & 30.00 & 57.54 & $94.70 \pm 0.67$ & 0.71 \\
\hline
\end{tabular}

\begin{tabular}{|c|c|c|c|c|c|}
\hline \multirow{3}{*}{ Compound } & \multicolumn{4}{|c|}{$\begin{array}{c}\text { TABLE-5 } \\
\text { PRECISION OF THE ANALYTICAL RESULTS }\end{array}$} & \\
\hline & \multirow{2}{*}{ Fortified Conc. $(\mu \mathrm{g} / \mathrm{mL})$} & \multicolumn{2}{|c|}{ Intraday $(\mathrm{n}=5)$} & \multicolumn{2}{|c|}{ Interday $(\mathrm{n}=5)$} \\
\hline & & Observed Conc. $(\mu \mathrm{g} / \mathrm{mL})$ & $\operatorname{Precision}^{\mathrm{a}}(\%)$ & Observed Conc. $(\mu \mathrm{g} / \mathrm{mL})$ & Precision $(\%)$ \\
\hline \multirow{3}{*}{ 5-HMF } & 3.00 & 3.02 & 0.60 & 2.98 & 0.78 \\
\hline & 7.50 & 7.52 & 0.81 & 7.69 & 0.53 \\
\hline & 30.00 & 14.99 & 0.19 & 14.91 & 0.13 \\
\hline \multirow{3}{*}{ Albiflorin } & 6.00 & 6.08 & 2.03 & 5.97 & 0.63 \\
\hline & 15.00 & 15.08 & 1.93 & 15.21 & 1.04 \\
\hline & 30.00 & 29.98 & 0.49 & 29.90 & 0.25 \\
\hline \multirow{3}{*}{ Paeoniflorin } & 10.00 & 10.09 & 0.97 & 10.01 & 1.78 \\
\hline & 25.00 & 24.71 & 0.96 & 24.75 & 1.28 \\
\hline & 50.00 & 50.13 & 0.21 & 50.12 & 0.26 \\
\hline \multirow{3}{*}{ Liquiritin } & 4.00 & 3.94 & 0.84 & 3.97 & 1.39 \\
\hline & 10.00 & 10.00 & 0.19 & 10.04 & 0.80 \\
\hline & 20.00 & 20.01 & 0.07 & 19.98 & 0.19 \\
\hline \multirow{3}{*}{ Ferulic acid } & 2.00 & 2.02 & 0.46 & 2.00 & 1.20 \\
\hline & 5.00 & 5.11 & 1.77 & 5.26 & 0.91 \\
\hline & 10.00 & 9.94 & 0.44 & 9.87 & 0.21 \\
\hline \multirow{3}{*}{ Cinnamic acid } & 1.00 & 0.99 & 0.87 & 0.99 & 0.77 \\
\hline & 2.00 & 1.96 & 0.63 & 1.98 & 0.19 \\
\hline & 4.00 & 4.02 & 0.16 & 4.01 & 0.08 \\
\hline \multirow{3}{*}{ Cinnamaldehyde } & 4.00 & 4.03 & 0.38 & 4.09 & 0.77 \\
\hline & 10.00 & 10.39 & 1.20 & 10.32 & 0.88 \\
\hline & 20.00 & 19.80 & 0.31 & 19.82 & 0.21 \\
\hline \multirow{3}{*}{ Glycyrrhizin } & 6.00 & 6.19 & 1.17 & 6.06 & 0.89 \\
\hline & 15.00 & 14.74 & 0.58 & 15.03 & 1.07 \\
\hline & 30.00 & 30.09 & 0.12 & 29.98 & 0.25 \\
\hline
\end{tabular}

medicine, Ssanghwa-tang extract. The concentrations of the eight identified compounds, 5-HMF, albiflorin, paeoniflorin, liquiritin, ferulic acid, cinnamic acid, cinnamaldehyde and glycyrrhizin in Ssanghwa-tang extract were 1.267, 2.908,
$12.261,1.903,0.993,0.148,2.308$ and $2.803 \mathrm{mg} / \mathrm{g}$, respectively (Table-6). Among these components, paeoniflorin of Paeoniae Radix was detected as the major compound compared with the others in Ssanghwa-tang extract. 


\begin{tabular}{|c|c|c|c|}
\hline \multicolumn{4}{|c|}{$\begin{array}{c}\text { TABLE-6 } \\
\text { CONCENTRATION OF THE EIGHT MARKER COMPOUNDS IN } \\
\text { SSANGHWA-TANG EXTRACT }(\mathrm{n}=3)\end{array}$} \\
\hline \multirow{2}{*}{ Compound } & \multicolumn{3}{|c|}{ Concentration $(\mathrm{mg} / \mathrm{g}$ ) } \\
\hline & Mean & SD & $\operatorname{RSD}(\%)$ \\
\hline 5-HMF & 1.267 & 0.002 & 0.189 \\
\hline Albiflorin & 2.908 & 0.002 & 0.085 \\
\hline Paeoniflorin & 12.261 & 0.032 & 0.259 \\
\hline Liquiritin & 1.903 & 0.000 & 0.018 \\
\hline Ferulic acid & 0.993 & 0.003 & 0.321 \\
\hline Cinnamic acid & 0.148 & 0.000 & 0.148 \\
\hline Cinnamaldehyde & 2.308 & 0.005 & 0.206 \\
\hline Glycyrrhizin & 2.803 & 0.003 & 0.118 \\
\hline
\end{tabular}

\section{Conclusion}

In this study, we have developed a simple, convenient and accurate HPLC-PDA method for the simultaneous analysis of eight marker compounds in the traditional Korean medicine, Ssanghwa-tang. The developed method showed good linearity, precision and recovery for evaluating the quality control of
Ssanghwa-tang. The developed HPLC-PDA method could be valuable for quality control and analyzing the biological activity of Ssanghwa-tang.

\section{ACKNOWLEDGEMENTS}

This research was supported by a grant (No. K13030) from the Korea Institute of Oriental Medicine.

\section{REFERENCES}

1. J. Hur, Donguibogam, Namsandang, Seoul, p. 447 (2007).

2. S.J. Kim, M.Y. Lee, I.S. Shin, C.S. Seo, H. Ha, J.I. Huh and H.K. Shin, Korean J. Herbology, 26, 39 (2011).

3. T.Y. Ha and D.I. Park, Korean J. Life Sci., 8, 366 (1998).

4. K.O. Lee, Korean J. Sports Sci., 8, 475 (1999).

5. B.N. Ann, S.K. Kim, C.K. Shim and Y.B. Chung, Yakhak Hoeji, 28, 207 (1984).

6. I.H. Kim and G.J. Hwang, Korean J. Pharmacogn., 12, 131 (1981).

7. S.Y. Lee, J.Y. Lee, W. Kang, K. Kwon, S.J. Oh, J.Y. Ma and S.K. Kim, Food Chem., 136, 450 (2013). 